\title{
The psychological portrait as a tool to improve the subjective well-being of the client in the context of personal sales
}

\author{
Elena S. Kiseleva $^{1 \mathrm{a}}$, Vasily V. Yeryomin ${ }^{1}$, ElenaV.Yakimenko ${ }^{1}$, Inna V. Krakoveckaya ${ }^{2}$, Sergey V. Berkalov ${ }^{2}$ \\ ${ }^{1}$ Tomsk polytechnic university, 634050 Lenina str., 30, Tomsk, Russia \\ ${ }^{2}$ Tomsk state university, 634050 Lenina str., 36, Tomsk, Russia
}

\begin{abstract}
The definition of the concept of relationship marketing is discussed. The notion of personal sale, which emphasizes the importance of knowing the psychology of customers, the ability to demonstrate significant competence and knowledge of modern techniques in sales by the seller is represented. The theory of marketing introduced by the concept of a "personal agent", most accurately reflects the activity of the seller in the context of relationship marketing. The necessity of the application of psychology in marketing is proved. This brief description of the four basic psychological concepts, which are the basis of the marketing strategy, is clarified by leading marketers. The three areas of application of differential psychology in marketing are suggested. The basis of the psychological techniques is represented by the typical characteristics of a person. The first point of the customer portrait is showed by the theory of spirits. The second point of psychological portrait is based on the theory of Socionics. The third point of the customer portrait refers to the theory of the types of perception of the world. Three stages of the process of building a psychological portrait of the client are proposed and described. Recommendations for dealing with clients of different psychological types are discussed. A technique of creation a psychological portrait of the client allows improving subjective well-being of customers and promotes the growth of the main indicators characterizing the effectiveness of personal sales.
\end{abstract}

\section{Introduction}

Current market conditions can be summarized as follows: the presence of the highest competition in the markets for goods and services, the growth of needs of customers, changes in customers' motives, the increasing importance of client capital, tough struggle for customer loyalty, increasing individualization of demand. In the context of relationship marketing companies need to solve an important problem. Its solution is connected with the search for effective tools of personal sales, meeting the needs of customers who are at high levels. It becomes important to take care not only about the economic well-being of the client. Personal agents people, who are engaged in personal sales as the medium of relationship marketing, are recommended to adopt an integrated approach in addressing the needs of clients and care about their subjective well-being. Making your customers happy is the main benchmark of personal agents of the 21 st century. We believe that one of the most effective tools of personal sales is a psychological portrait of the client. Despite rather serious research in the field of differential psychology, methodological approaches to the creation of a psychological portrait of the client need to be improved. The aim of the article is

\footnotetext{
${ }^{\mathrm{a}}$ Corresponding author: nirsip@yandex.ru
}

to provide a methodology of creating a psychological portrait of the client. In this procedure it is advisable to use a personal agent in personal sales carried out as the medium of relationship marketing. This action will allow receiving valuable benefits both the company and customers. To achieve the goal of research it is required to solve the following tasks. First, to give a definition of relationship marketing - a popular marketing concept. Second, to justify the increasing role of psychology in marketing. Third, to indicate the three main points of the psychological portrait of the client. Fourth, to propose and describe stages of the process of building a psychological portrait of the client. Fifth, to develop recommendations for dealing with clients of different psychological types.

\section{Theoretical and methodological aspects of creating a psychological portrait of the clients in the context of personal sales}

1.1 Potential of the application of scientific psychology in marketing and personal sales. 
Currently, the concept of relationship marketing is in its infancy and development. On the basis of analysis of the literature $[1,2]$, we give the following definition of the latest marketing concept. Relationship marketing is a modern paradigm, which is based on building, maintaining and developing high-level relationships with customers, especially the key, as well as employees, external organizations, suppliers and "needy", by addressing a broad range of real needs and demands of society. Features of the author's formulations of definitions are as follows. First, the vision of relationship marketing as a paradigm of marketing, as a concept is visual. Second, it is necessary to focus on building of relationships not only with customers, but also with employees, external organizations, suppliers and "needy". Third, there is the importance of meeting the needs of a wide range of stakeholders and society. Thus, the modern marketing environment meets complex needs of the representatives of the groups that are at high levels. The more sophisticated customer needs are met, the higher the level of subjective well-being is.

In his works, E. Diener [3] introduced the concept of "subjective well-being." In his opinion, subjective wellbeing consists of basic components: the satisfaction of pleasant emotions and unpleasant emotions. All these components together form a single indicator of subjective well-being. E. Diener says that most people appreciate what has happened to them in terms of "good - bad". This intelligent assessment always is under a correspondingly dyed emotion. Subjective well-being should demonstrate how one person is happier than the other. Related concepts for the term "subjective wellbeing" is "optimism", "life satisfaction", "happiness". We share with E. Diener that a subjective well-being should be understood as integral socio-psychological education, including assessment and man's relation to his life and himself, and bearing in itself the active principle. Such an understanding of the subjective well-being requires the allocation of all three components of mental phenomena: cognitive, emotional and behavioral. This phenomenon is characterized by subjectivity, positivity and global dimension.

In our view, C. Ryff $[4,5]$ most successfully revealed and described the phenomenon of psychological wellbeing. C. Ryff successfully compiled and identified six basic components of psychological well-being: autonomy, environmental management, personal growth, positive relations with others, a purpose in life, selfacceptance. One can assume that the application of methods of creating a psychological portrait of the client in practice will have a positive impact on the level of both the subjective and psychological well-being of clients.

We share the opinion of K. Möller and A. Nalinen that relationship through the line "producer-consumer" is still the main focus of both the relationship marketing and marketing science as a whole [6]. In our opinion, the main resource for the implementation of a successful process of "client's reproduction" is employees who have contact with customers. This fact underlines the importance of development in the field of personal sales. Under the personal sales we understand the relations between clients and personal agents (company) on the basis of personal contact between the two sides without any means of communication in connection with the sale of goods (services) or other interaction, whose effectiveness depends on knowledge of the psychology of customers, the ability to demonstrate relevant competence and knowledge of modern technologies of sales by private.

A thorough understanding of the client is the only solid basis for the development of marketing strategies in the context of relationship marketing. According to many scientists, the foundation of a successful business is the availability of the main benchmark in the study of the psychology of consumers. Next four basic psychological concepts taken as a basis for marketing strategy by known marketers are designated.

In the classical concept of Ph. Kotler [2], the main role is played by the psychology of motivation and needs. This concept is called classical or needmotivational. Ph. Kotler believes that first of all marketing is to promote the production of quality products and provide quality services. In this case, efforts to promote products should be minimal. Buyers always exist objectively; they should not be created artificially by means of advertising or manipulating consumer psychology. Requirements should be timely and accurately met. As a result of this process there will be long-lived brands.

The concept of J. Trout [7], which is called marketing of concepts, general and social psychology is prevailed. J. Trout said that the main principle of marketing is not only the improvement of consumer properties of the goods but product positioning in the minds of consumers as to be the best one. The main thing is not the product itself and efforts to fight against competitors. Here is a psychological basis of marketing. It does not work with the product but with the images of consumers comparing different products.

The concept of sensory marketing, founded by $\mathrm{M}$. Lindstrom [8], is based on the of consumer's analyzers of psychophysiology and psychology of religion. This concept is called sensory marketing and reduced to two positions. First, any product must simultaneously affect five sensory analyzers: sight, hearing, smell, touch, taste. Second, the brand needs to cause the consumer religious feelings. A consumer must believe that she/he bought the best in the market.

The concept of neuromarketing proposed by J. Zaltman [9] is based on cognitive psychology and neuropsychology. The author considers the important thing in marketing is a decision-making process management. As part of this concept, the foundations for the emergence of "cool" brand are pledged in the subconscious mind of man. They need to be extracted out in the form of information and return to the consumer in the form of metaphors.

It should be noted that this branch of psychology such as differential psychology has great potential for use in marketing and personal sales. In our opinion, the main applications of differential psychology are: segmentation of consumers, consumer behavior, and psychological typology of consumers. . Application of 
psychological concepts in marketing by scientists worldwide shows a marked increase in the role of psychology in marketing. Relationship marketing also requires the application of theoretical and practical development of psychology in marketing for the construction, maintenance and development of highlevel relationships with stakeholders. The effectiveness of personal sales primarily depends on the competence of the individual agents. In our opinion, one of the most effective tools for managing of personal sales competency model is a personal agent. A good example is the universal competence model, which contains twenty-four competencies [10]. We believe that particular importance is the competence called "Knowledge of psychology of customers." To demonstrate this competency, private agents must be able to create a psychological portrait of the client.

\subsection{Technique of creation of a psychological portrait of the client}

The psychological portrait of the client is an effective tool for both personal sales and marketing. Its effectiveness is dealt with the fact which allows precisely and consistently interacts with customers. If such a tool is not used, an effective communication with the client is out of the question. In turn, its use is guaranteed to lead to the construction of high-quality and efficient communication with the customer.

In our view, the basis for building a psychological portrait of the customer should be known in the psychology of the main classifications as sustainable and relatively resistant psychological characteristics of typical human. In our opinion, the psychological portrait of the client should be composed of three facets which are based on the following theories: the theory of temper, socionic theory and the theory of the types of thinking (perception of the world). In other words, we offer three main areas of customer segmentation. It should be noted that recently a psychographic segmentation of customers or psychological principle get special value. In this segment the customers are divided into groups on the basis of belonging to a social class, lifestyle, or personality characteristics. Further, it is advisable to briefly describe three psychological theories underlying the psychological portrait of the client.

It is known that temper - these are inborn human characteristics that determine the dynamic characteristics of the intensity and speed of response, the degree of emotional excitability and balance, particularly adaptation to the environment. The temper has an innate nature, resulting in the inability to change from one to another during the life of any human being. Each temper has its positive and negative sides. Temper of action is a characteristic of choleric and phlegmatic, and emotional temper - sanguine and melancholic.

Socionics offer classification, consisting of sixteen personality types with their empirical description. These socio types are allocated on the basis of affiliation to different poles of personality: extrovert - introvert, sensory - intuit, logician - aesthete, judger - perceiver It should be noted that the first preference determines from whence a person draws strength from the outside (extraversion) or inside (introversion). The second preference determines how people gather information about the world - directly and consistently (sensing) or figuratively and spontaneously (intuition). The third preference characterizes the decision - objective and impartial (logic) or subjective and based on the factors of interpersonal relations (ethics). The fourth preference describes how people live - acts decisively on the plan (rationality) or makes spontaneous decisions (irrationality).

One of the main features of human thinking is her/his perception of the world. There are three major types of thinking, specified on the basis of human sensory systems - visual (visual), hearing (auditory) and feeling. Depending on the dominant type of thinking all people can be divided into visual, auditory learners and kinesthetic learners.

Everyone has the five senses, but one or maximum two systems may be leading or representative.

Methods of creating a psychological portrait are based on three main stages. We offer the following stage of the process of building a psychological portrait of the client. From a strategic point of view, at the first stage a personal agent must conduct customer segmentation in three key identified areas using visual diagnostics. More information about the nature and characteristics of the visual diagnostics can be found in the literature on psychology. At the second stage the seller must fix the result in the customer database for reliable preservation of information and use it in the future. Over time, the database should make additional information or modify existing one. Third, the personal agent must demonstrate a desirable model of behavior through personal contact with the client. To do this, it is advisable to make recommendations to work with clients of different psychological types.

\section{Recommendations for work with clients of different psychological types}

\subsection{Recommendations for work with clients of different tempers}

As we know, there are four types of human temper. The following are best practices for personal agents to work with a client-choleric person, client-sanguine, clientphlegmatic and client -melancholic.

\subsubsection{Recommendations for work with a client- choleric person:}

- $\quad$ to use the best tactics of persuasion - from practical or logical argumentation to the emotional;

- to direct the efforts on customer retention and to strive to get her/his attention again and again;

- to adhere the confident behavior, talk straight and not to argue with the customer;

- to suggest how usage of the product allows the customer to get better; 
- to take into account the needs of customers in the recognition and respect by others;

- to consider the possible behavior of the client demanding, lack of patience and temper;

- to offer actively new, prestigious and exclusive products and projects associated with the risk.

\subsubsection{Recommendations for work with a client- sanguine person:}

- to use the best tactics of persuasion - from the emotional to the practical reasoning or logic;

- to conduct a dialogue with a positive argument (motivation of success, enjoyment and achievement);

- $\quad$ to be patient in a situation of "verbal flow" from the buyer;

to tactfully remind the customer about the main topic of conversation in the event of her/his talkative on abstract themes;

to show enthusiasm, strive to be happy, cheerful and energetic;

- to openly show interest in the customer, thus giving her/him the opportunity to feel meaningful.

\subsubsection{Recommendations for work with a client- phlegmatic person:}

- $\quad$ to use the best tactics of persuasion - from practical or logical argument to the emotional;

- to direct its efforts on attracting customers and the making the first deal;

- to take into account the predisposition for loyal behavior towards market linkages;

- to operate with facts - accurate statistical data and calculations;

- to monitor the truthfulness and accuracy of her/his speech;

- to offer a secure, reliable and proven commodities by other people to make a decision;

- to refrain from proposals of new products and projects related to risk.

\subsubsection{Recommendations for work with a client- melancholic person:}

- $\quad$ to use the best tactics of persuasion - from practical or logical argument to the emotional;

- to direct its efforts on attracting customers and the making the first deal;

- $\quad$ to consider a predisposition to loyal behavior towards market communications;

- $\quad$ to operate with facts - accurate statistical data and calculations;

- to be aware that strong positive emotions from your side will not affect the reduction of the distance to the customer making a purchase;

- to monitor the truthfulness and accuracy of his speech.

2.2 Recommendations for work with clients of different socionic types
As we know, socio types are allocated on the basis of affiliation of the person to different poles. Here are some pieces of practical advice to personal agents for working with extravert, introvert, sensory, intuit, logician, aesthete, judger.

\subsubsection{Recommendations for work with a client- extrovert:}

- to confidently engage in interpersonal contact with the consumer, demonstrating openness and attentiveness and desire to communicate;

- to be patient in a situation of "verbal flow" from the buyer; support all topics of conversation in the communication process, particular with no relation to the purchase;

- to give advice, guidance and evaluation in the selection process by the consumer;

- to support buyers' confidence in themselves;

- to make a compliment on her/his good taste and beautiful appearance;

- to invite another seller to express her/his opinion in a situation where the client has doubts about her/his choice;

- to offer the best bonus - a visit to the restaurant.

\subsubsection{Recommendations for work with a client- introvert:}

- to engage in interpersonal contact with the client only when he is willing to communicate;

- to avoid haste in their actions and give consumers chance to make a purchase decision by himself;

- to listen carefully to the buyer and not to interrupt his speech;

- to ask gently questions concerning the purchase;

- to find opportunities to create quiet and cozy atmosphere in the place of communication with the consumer;

- to offer the best bonus - a concert of instrumental band, dinner for two in a quiet comfortable surroundings and other places, where the customer will be able to be alone or with other person.

\subsubsection{Recommendations for work with a client- sensory:}

- to demonstrate product details including specific properties and operating conditions; - to respond to the client specifically, clearly, emphasizing the time interval "here and now"; - to be prepared for the change of mind from the part of the buyer and allow her/him to change her/his mind, provide the customer information about the level of prices for similar goods in other stores;

- to offer the customer opportunity to touch, feel or try on your favorite thing; check the text in the contract, presentations or writing to eliminate possible spelling errors that the client is inclined to notice;

to apply standard approaches when working with a client, except for the original decision on her/his part; 
to focus on financial benefits, long-term warranty service, convenience and comfort.

\subsubsection{Recommendations for work with a client-intuit:}

- to demonstrate items, limited to its general description, do not go into the finer details and avoid the transfer of parts of it;

- to focus on brand awareness and prestige of the purchase;

- to provide a nice decoration of the room in which the meeting is;

- to have perfect appearance: neat, stylish and expressive;

\subsubsection{Recommendations for the client-logician:}

- to emphasize the benefits of purchase of goods in terms of "price-quality";

- to keep our promises and avoid inconsistency between words and actions;

- to affect the client, taking into account the availability of good, informal relations;

- to offer good loan terms, payment by installment or a significant discount;

- to provide favorable conditions for future transactions;

- to give specific facts and statistics in the course of argument in favor of the product;

- to ignore the symptoms of rigidity and lack of sensitivity from part of the client;

- to understand that the most important thing for client a benefit of the transaction.

\subsubsection{Recommendations for work with a client- aesthete:}

- to focus on the construction of preferred interpersonal relationships with clients by creating a friendly motive of communication;

- to show respect, commitment and kindness to the client;

- to support the initiative of the buyer to develop informal communication;

- to smile to the client at the time of the meeting and parting with them;

- to provide the greatest possible attention to the client; -to participate in projects that are aimed at helping other people;

- to influence the choice of the consumer only if you are sure of its feasibility;

- to understand that the most important for the client is the presence of warm, good and desirable relationship.

\subsubsection{Recommendations for work with a client - judger:}

- to develop systematic approach to work with the client;

- to focus on the profitable "price-quality" product;

- to demonstrate their competence and respond to customer's questions honestly, clearly and specifically;
- to consider customer confidence in buying product and not offer other goods;

- to be patient for possible displays of categoricity and demands from the client;

- to make quick sale, eliminating the possibility of a moment reflection and expectations of the buyer;

- to arrange meetings with the buyer in the same place;

- to come to a meeting at appointed time.

\subsubsection{Recommendations for work with a client - perceiver:}

- to adhere to free approach to work with the client;

- to offer a variety of alternatives in the process of offer and the sale of goods;

- to take into account of freedom of the client at any stage of working with her/him;

- to offer other products to the customer in view of his lack of confidence in the fact that she/he wants to purchase;

- to be patient with indecision on the part of the buyer and help to make a choice;

- to quietly relate to frequent change of mind in the selection of goods by the customer; allowance to make a purchase only if the product is really necessary to the consumer;

- to provide the ability to return goods to customers because of their uselessness.

\subsection{Recommendations for work with clients of different types of perception}

It is known that there are three major types of thinking (the perception of) a person designated on the basis of human sensory systems. The dominant type of thinking of all people can be divided into visuals, auditory learners and kinesthetic learners. The followings are best practices for private agents to work with the visual learners, auditory learners and kinesthetic learners.

\subsubsection{Recommendations for work with a client - visual learner:}

- to use words and phrases that are used by the clients, associated with the work of the organs of vision;

- to have excellent appearance - tightened figure, beautiful clothes, perfect makeup, well-groomed hair and nails;

- to ensure that the interior of the place of sale in different beauty, exquisite taste and bright accents;

- to comply with the desired distance for the client;

- to offer products that are distinguished by the beauty and elegance, have a beautiful shape and a wide range of colors;

- to show the goods to the customer, including in the presentation of a lot of bright images and photos showing the goods;

\subsubsection{Recommendations for work with a client - auditory learner:}


- to use the words and phrases that are used by the client, work-related hearing;

- $\quad$ to speak in a pleasant voice, adhere to a relaxed manner of speech and use intonation accent;

- $\quad$ to ensure that the point of sale was quality music system and sounded pleasant music;

- $\quad$ to comply with the desired distance for the client;

- to offer products that are able to provide quality sound emitting minimal noise when using natural;

- to fill in personal communication with elements of direct marketing - telephone calls;

- to pay attention to the music in the place where a business meeting is held.

\subsubsection{Recommendations for work with a client - kinesthetic learner:}

- to use the words and phrases widely used by the client, associated with feelings and sensations;

- to be nice to touch clothing and use a good perfume;

- to ensure that the place of sale was equipped with easy-to-use and pleasant atmosphere to touch objects, providing maximum comfort to the customer at the physical level;

- $\quad$ to comply with the desired distance for the client;

- offer products for maximum comfort and comfort to the clients in the course of their use;

- to give the opportunity to test the product - pay attention to high level of food and beverages in the framework of a business meeting.

\section{Conclusion}

Thus, to solve practical problems of relationship marketing it is necessary to refer to the research of psychological mechanisms of thinking and behavior of the customer. Communication in the context of personal sales, created by using a psychological portrait of the client, has a positive impact on both the client and the company. On the one hand, the use of such an effective tool for personal sales as a psychological portrait can improve the subjective well-being of clients. On the other hand, it promotes the growth of the main indicators characterizing the effectiveness of personal sales in the context of relationship marketing. To main indicators, we attribute satisfaction, trust, engagement, loyalty and comprehensive income. It is important to companies in the course of their business activities adhere to the principles of relationship marketing concepts presented in the literature [11]. The importance of the psychological portrait of the client confirmed the following principles recognized by the scientific community: the principle of the use of interdisciplinary approaches to marketing activities; the principle of the importance of segmenting customers based on behavioral and psychological factors; the principle of identifying and satisfying a wide range of customer needs; the principle of emphasis on creating positive feelings, emotions, feelings and moods of an individual approach to each client.
We consider it ideological to offer a fourth facet of a psychological portrait based on the psychological theory of personality accentuation of mood. This topic is to be developed later.

\section{Acknowledgment}

This work was performed by the authors in collaboration with Tomsk Polytechnic University within the project

"Evaluation and enhancement of social, economic and emotional wellbeing of older adults" under Agreement No.14.Z50.31.0029

\section{References}

1. J. Egan, Relat.marketing: exploring relationship strategies in marketing. $2^{\text {nd }}$ ed. (New York: Financial Times/Prentice Hall, 2004)

2. Ph. Kotler, Market. manag (New York: Prentice Hall., 2003)

3. E. Diener, Psychol. Bulletin, 95, (1984)

4. C.D. Ryff, Journ. of Person. and Social Psychology, 57, (1989)

5. C.D. Ryff, Current Direct. in Psycho 1. Sc., 4, (1995)

6. K. Möller, A. Halinen, Journ. of Market. Management, 16, (2000)

7. J. Trout, Big brands, big trouble : lessons learned the hard way (New York : Wiley (2001)

8. M. Lindstrom, Buyology : Truth and lies about why we buy (New York : Broadway Books, 2010)

9. G. Zaltman, How Customers Think: Essen.Insights into the Mind of the Markets (Boston: Harvard Business School Press, 2003)

10. E.S. Kiseleva, Procedia - Social and Behavioral Sciences, 166, (2014)

11. E.S. Kiseleva, The European Proceedings of Social \& Behavioural Sciences EpSBS, 7, (2015) 